\title{
An unusual cause of 'pain in the neck'
}

\author{
S Manjunath, DB Trash
}

A 76-year-old woman presented to her general practitioner with pain in the throat and neck, worse on coughing and associated with swelling. Twenty-four hours earlier she had undergone flexible sigmoidoscopy and laser treatment with Nd:YAG laser for a sessile tubulovillous adenoma of the rectum. She had undergone laser treatment uneventfully three times before at four-weekly intervals and the tumour had regressed macroscopically almost completely. There was no abdominal pain, vomiting or bleeding per rectum. The abdomen was soft, non-tender and the bowel sounds were normal. There was diffuse swelling of the neck with crepitus. A plain Xray of the abdomen (figure 1) and an erect chest X-ray (figure 2) were done:

\section{Department of Gastroenterology, Manor Hospital, Walsall, West Midlands, UK $S$ Manjunath DB Trash}

Correspondence to Dr S Manjunath, Endoscopy Suite, Manor Hospital, Moat Road, Walsall WS2 9PS, West Midlands, UK

Accepted 4 March 1997

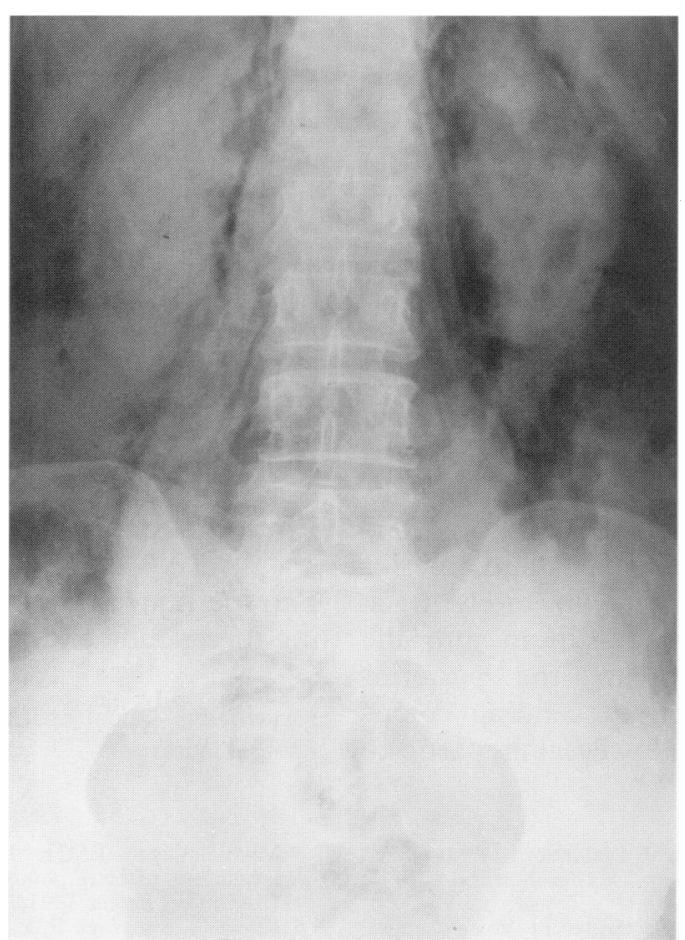

Figure 1 Plain abdominal X-ray

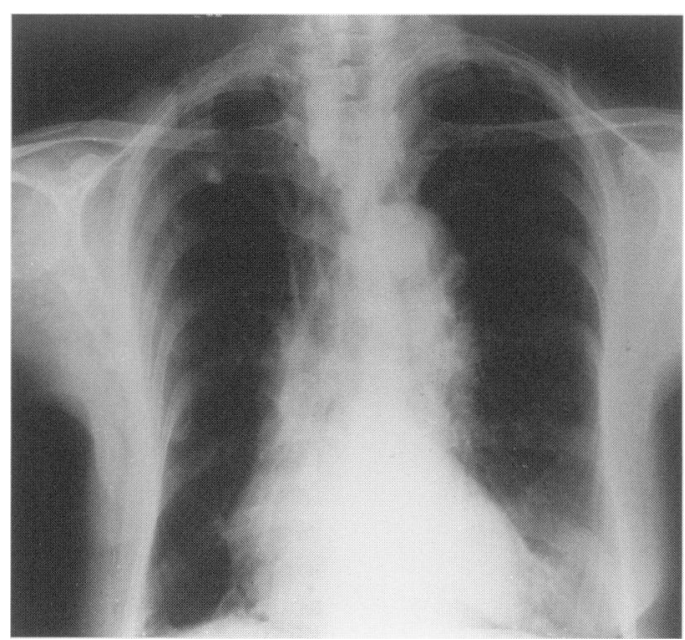

Figure 2 Chest X-ray

\section{Questions}

1 What are the radiological findings? 2 What is the diagnosis? 
Answers

\section{QUESTION 1}

The chest X-ray shows pneumomediastinum and surgical emphysema of the neck, better seen on the right side. The $\mathrm{X}$-ray of the abdomen shows extensive retro-pneumoperitoneum with extension along both psoas muscles into the posterior spaces outlining the kidneys.

\section{QUESTION 2}

Extraperitoneal perforation of the rectum.

This patient responded very well to conservative treatment with intravenous fluids and antibiotics. She was symptom-free after 48 hours. The surgical emphysema had regressed completely and she was discharged from the hospital. A barium enema done four days later was normal and there was no residual leak.

\section{Discussion}

Fiber-optic endoscopes are frequently used in the diagnosis and therapy of colorectal lesions. These procedures can cause perforation of the bowel in $0.5 \%$ to $3 \%$ of cases. ${ }^{1}$ The clinical presentation and signs vary, depending on whether the perforation is intraperitoneal or extraperitoneal.

A transmural rectal tear below the peritoneal reflection leads to passage of gas into perirectal fat and pelvic floor soft tissues. It then extends bilaterally along the psoas muscles and posterior pararenal spaces into the flank and anterior abdominal wall. ${ }^{1}$ The gas can rarely track further up along the mediastinum into the neck. Perforations involving the posterior aspects of ascending and descending colons are also extraperitoneal. However, they tend to

1 Ghahremani GG. Radiological evaluation of suspected gastrointestinal perforations. Radiol Clin North Am 1993; 31: $1219-34$

2 Kirk J, Staren ED, Franklin J, Saclarides TJ. Voice changes: an initial manifestation of colonic perforation (letter). Gastrointest Endosc 1994; 40: 125.

3 Fitzgerald SD, Denk A, Flynn M, Longo WE, Vernava AM. Pitzerald SD, Denk A, Flynn M, Longo WE, Vernava AM. neck. An unusual manifestation of colonoscopic perforation. Surg Endosc 1992; 6: 141-3. be locally contained and remain clinically silent for several hours to days. ${ }^{1}$ The usual finding on abdominal X-ray is localised gas collection in the affected paracolic region or the anterior pararenal space on the ipsilateral side. It presents as mottled lucency between the medial border of psoas muscle and the spine, but usually does not extend to the flank or the contralateral side. ${ }^{1}$ The presentation of extraperitoneal perforation of the rectum as surgical emphysema of the neck, voice changes, pneumomediastinum or pneumopericardium is rare and is limited to case reports. ${ }^{2,3}$

Laser ablation is a useful option for large sessile colorectal polyps that cannot be surgically removed or in inoperable patients or patients refusing surgery. Colorectal perforation following laser ablation is a very rare complication amounting to less than $0.5 \%$ in a large series. ${ }^{4}$

Conservative management is advocated for silent colorectal perforations and in patients with mild or localised symptoms. A suspected large perforation, generalised peritonitis or failure to improve on conservative management are indications for surgery. If the patient does not clearly fall into either of these groups the management depends on the endoscopist's assessment of the size, mechanism and time of perforation, the degree of bowel preparation, delay in diagnosis, overall condition of the patient and any associated colonic pathology. ${ }^{5}$

\section{Final diagnosis}

Extraperitoneal perforation of rectum following therapeutic endoscopy.

Keywords: rectal perforation, colonoscopy, laser photoablation

4 Mathus-Vligen EMH, Tytgat GNJ. The potential and limitations of laser photoablation of colorectal adenomas. Gastrointest Endosc 1991; 37: 9-17.

5 Kavin H, Sinicrope F, Esker AH. Management of perforation of the colon at colonoscopy. Am $\mathcal{F}$ Gastroenterol 1992; 87: $161-7$. 